\title{
Effects of climate change on phenology and primary productivity in the desert steppe of Inner Mongolia
}

\author{
Fang HAN ${ }^{1,2}$, Qing ZHANG ${ }^{1,3}$, Alexander BUYANTUEV ${ }^{4}$, JianMing NIU ${ }^{1,3 *}$, PengTao LIU $^{1,2}$, XingHua $\mathrm{LI}^{2}$, \\ Sarula KANG ${ }^{1}$, Jing ZHANG ${ }^{1}$, ChangMing $\mathrm{CHANG}^{1}$, YunPeng $\mathrm{LI}^{2}$ \\ ${ }^{1}$ School of Life Sciences, Inner Mongolia University, Hohhot 010021, China; \\ ${ }^{2}$ Meteorological Bureau of Inner Mongolia, Hohhot 010051, China; \\ ${ }^{3}$ Sino-US Center for Conservation, Energy and Sustainability Science in Inner Mongolia (SUCCESS), Hohhot 010021, China; \\ ${ }^{4}$ Department of Geography and Planning, the State University of New York, NY 12222, USA
}

\begin{abstract}
Variations in temperature and precipitation affect local ecosystems. Considerable spatial and temporal heterogeneity exists in arid ecosystems such as desert steppes. In this study, we analyzed the spatiotemporal dynamics of climate and vegetation phenology in the desert steppe of Inner Mongolia, China using meteorological data (1961-2010) from 11 stations and phenology data (2004-2012) from 6 ecological observation stations. We also estimated the gross primary production for the period of 1982-2009 and found that the annual mean temperature increased at a rate of $0.47^{\circ} \mathrm{C} /$ decade during 1961-2010, with the last 10 years being consistently warmer than the 50 years as an average. The most significant warming occurred in winters. Annual precipitation slightly decreased during the 50-year period, with summer precipitation experiencing the highest drop in the last 10 years, and spring precipitation, a rise. Spatially, annual precipitation increased significantly in the northeastern and eastern central areas next to the typical steppe. From 2004 to 2012, vegetation green-up and senescence date advanced in the study area, shortening the growing season. Consequently, the primary productivity of the desert steppe decreased along the precipitation gradient from southeast to northwest. Temporally, productivity increased during the period of 1982-1999 and significantly decreased after 2000. Overall, the last decade witnessed the most dramatic climatic changes that were likely to negatively affect the desert steppe ecosystem. The decreased primary productivity, in particular, decreases ecosystem resilience and impairs the livelihood of local farmers and herdsmen.
\end{abstract}

Keywords: desert steppe; green-up; gross primary productivity; phenology; precipitation; temperature

Citation: Fang HAN, Qing ZHANG, Alexander BUYANTUEV, JianMing NIU, PengTao LIU, XingHua LI, Sarula KANG, Jing ZHANG, ChangMing CHANG, YunPeng LI. 2015. Effects of climate change on phenology and primary productivity in the desert steppe of Inner Mongolia. Journal of Arid Land, 7(2): 251-263. doi: 10.1007/s40333-014-0042-4

A $0.74^{\circ} \mathrm{C}$ increase in the global average temperature during 1906-2005 has led to massive snow and ice melting, sea level raising, and regional extreme weather events increasing (IPCC, 2007). While these changes have attracted great concerns for governments, scientific communities, and general public around the world, the associated ecological transformations such as vegetation processes and primary productivity are also very important and need to be understood and assessed. Plant phenology, which is related to seasonal and inter-annual dynamics of vegetation, is a valuable indicator of climate change and ecological transformation. It is thus helpful in assessing the effects of global climate changes on short-term variations in terrestrial ecosystem processes (Chen et al., 2005). Plant phenological responses to climate changes reported in the literature are fairly inconsistent (Walther et al., 2002). Most studies have reported earlier green-up and delayed senescence of plants with an overall lengthening of growing season

\footnotetext{
*Corresponding author: JianMing NIU (E-mail: jmniu2005@163.com)

The first and second authors contribute equally to this work.

Received 2014-02-24; revised 2014-08-26; accepted 2014-09-15

(C) Xinjiang Institute of Ecology and Geography, Chinese Academy of Sciences, Science Press and Springer-Verlag Berlin Heidelberg 2015
} 
in response to recent temperature elevations. Others documented the decreasing trend in the length of the growing season resulting from both the earlier onset of spring phenophases and even more significant temporal advancement of autumn phenophases (Edwards and Richardson, 2004; Cleland et al., 2007). However, some studies have found opposite patterns where green-up was delayed despite the rise in temperatures (Walther et al., 2002; Menzel et al., 2006). Knowledge of climate change-induced shifts in phenology is important for understanding the changes in primary productivity and ultimately, in the structure and functioning of ecosystems (Stenseth et al. 2002; Bai et al., 2004; Cornelissen et al., 2007). The impact of climate change on productivity has also become a focus of active research among scientists. Studies have found that the productivities of different ecosystems not only have different sensitivities to climate change (Stenseth et al., 2002; Piao et al., 2009; Ma et al., 2010), but also respond to temperature elevations in three different ways: increase, decrease or no change (Fang et al., 2005; Piao et al., 2006; Bai et al., 2008).

Regional differences in climate changes entail differences in ecosystem responses to them. Therefore, understanding global climate trends and developing strategies to cope with environmental changes at the regional level may require detailed climate-ecosystem analyses at the appropriate scale. Grassland is an example of a highly vulnerable ecosystem that is predicted to undergo significant ecosystem changes. The change in the primary productivity and phenology of the Inner Mongolia grassland, an essential part of the Eurasian steppe, has attracted considerable attention during the last 50 years. However, more researches were focused on the typical steppe, and showed that both the length of the growing season and primary productivity were increased, and precipitation was the main driver (Piao et al., 2006; Yun et al., 2008; Gu et al., 2012). Due to very dry climate along with high temperatures and little rainfall, the desert steppe in Inner Mongolia is highly susceptible to the process of desertification. Currently, the desert steppe serves as an important sheep-raising base despite its low productivity. It is of great significance to the development of grassland animal husbandry (Inner Mongolia-Ningxia Joint Inspection Group of Chinese Sciences of Academy, 1985). Due to harsh and varia- ble climatic conditions, the desert steppe ecosystem has been very fragile and sensitive to environmental changes. There is limited knowledge on the way in which this unique ecosystem responds to climate changes and its role in the global carbon cycle.

In this study, we aimed to quantify the direction and magnitude of the recent responses of desert steppe in Inner Mongolia. We used historical data, field observations and simulation modeling to characterize the climate changes in this area. Spatiotemporal analyses of phenological records and vegetation productivity helped us understand the climate trends in the desert steppe of Inner Mongolia in the past 50 years, the effects of climate changes on plant phenology, and the spatio-temporal patterns of vegetation productivity in the desert steppe along with their responses to climate changes. This study would thus provide valuable scientific information for developing mitigation strategies of disadvantage factors resulted in climate change for this vulnerable ecosystem.

\section{Materials and methods}

\subsection{Study area}

The desert steppe of Inner Mongolia is located in northern China along the border with Mongolia. It stretches between $106.07^{\circ}-114.48^{\circ} \mathrm{E}$ and $40.52^{\circ}-$ $45.10^{\circ} \mathrm{N}$, with the elevations ranging $964-1,649 \mathrm{~m}$. The continental climate is characterized by an annual average temperature of $0.8^{\circ} \mathrm{C}-5.3^{\circ} \mathrm{C}$ and an annual precipitation of $135-311 \mathrm{~mm}$, most of it occurring during July-September. Scarce vegetation developed over brown soils consists of desert steppe communities of simple structure. The dominant grass species in the area are Stipa klemenzii, Stipa breviflora and Cleistogenes songorica (Inner Mongolia-Ningxia Joint Inspection Group of Chinese Academy of Sciences, 1985).

\subsection{Data analysis}

We used monthly temperature and precipitation data collected from 11 meteorological stations (Fig. 1) in the desert steppe of Inner Mongolia during 1961-2010 (data for the Urad Rear Banner were available only for 1974-2010). These data were divided into 5 decades for further analyses. Temporal trends were analyzed for annual mean values and separately for spring 


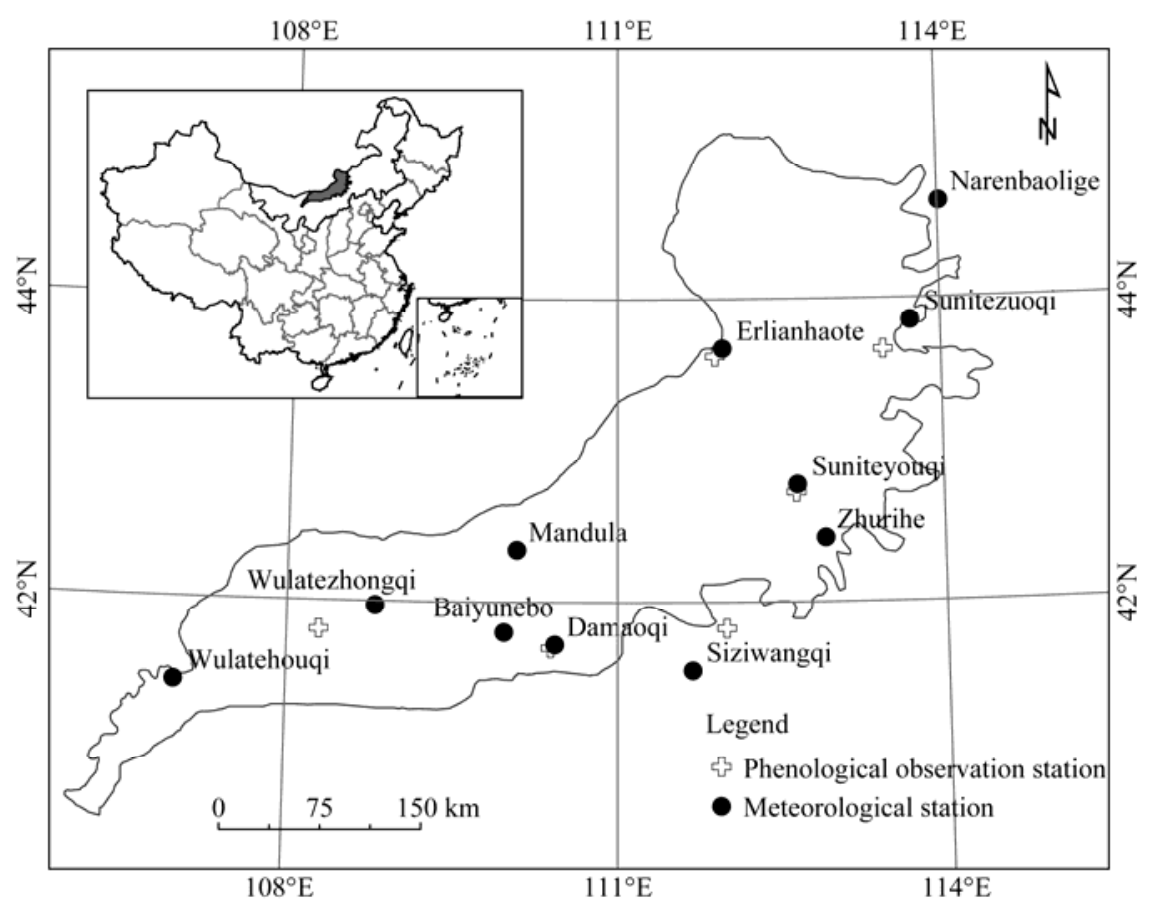

Fig. 1 The meteorological and phenological observation stations of the study area

(March-May), summer (June-August), autumn (September-November) and winter (December-February). Any missing data were substituted via interpolation from the records of nearby stations.

In order to analyze the spatial variation of temperature and precipitation in the entire study area, corresponding $1 \mathrm{~km} \times 1 \mathrm{~km}$ grids were created for each decade using kriging spatial interpolation. We assessed the temporal trends of these variables by regressing them against time (year) on a pixel by pixel basis (Eq. 1).

$$
y=\mathrm{a} x+\mathrm{b} \text {. }
$$

Where $x$ is the year, a represents the slope of the regression trend line, and $b$ is the intercept. Positive slopes signify increasing temporal trends and negative ones correspond to decreasing trends. The absolute value of the slope reflects the degree of change.

\subsection{Analysis of phenological data}

Plant phenological data, including green-up and senescing dates of dominant species (Table 1), were collected at 6 ecological observation stations (Fig. 1) during 2004-2012. Ten fixed plants (clumps) of the representative species were monitored every morning or on the mornings of even-numbered days. Green-up date is referred to the date when more than $50 \%$ of the green parts of a plant that grow above the ground, namely shoots and sprouts, appeared. Senescing date referred to the period when about $2 / 3^{\text {rd }}$ of the roots and shoots of the monitored species died or discolored. Phenological data were recorded using a standard day of the year, with 1 January as the first day of the year. The length of the growing season was calculated as the difference between senescing and green-up dates. Temporal trends were analyzed for the green-up date, senescing date and the length of the growing season, respectively.

\subsection{Analysis of primary productivity}

Gross primary productivity (GPP) is the rate at which green plants produce biomass by assimilating carbon dioxide through photosynthesis per unit time period. It lays the basis for carbon cycle in ecological systems (Bachu and Adams, 2003). GPP is important for estimating the production capacity of the earth and evaluating the resilience of ecological systems. In this study, the GPP of the desert steppe was estimated using the Eddy Covariance-Light Use Efficiency (EC-LUE) model. EC-LUE model is the light energy use efficiency model developed based on the Eddy- 
Table 1 The trend of plant phenological change in the desert steppe of Inner Mongolia

\begin{tabular}{ccccc}
\hline Weather station & Observation species & Green-up (Day/annual) & Senescing & Length of growing season \\
\hline Erlianhaote & Stipa klemenzii & -0.22 & -2.03 & -1.82 \\
Sunitezuoqi & Stipa klemenzii & -1.73 & 1.29 & 2.87 \\
Suniteyouqi & Stipa klemenzii & 0.05 & -0.63 & -1.09 \\
Wulatezhongqi & Stipa klemenzii & -1.00 & -2.82 & -2.05 \\
Damaoqi & Stipa breviflora & 4.05 & -0.42 & -4.17 \\
Siziwangqi & Leymus chinensis & -0.84 & 1.09 & 1.93 \\
& & -0.098 & -1.098 & -1.32 \\
\hline
\end{tabular}

Note: Negative value indicates advanced phenology, positive value indicates delayed phenology.

Covariance carbon flux data collected at a number of sites (Yuan et al., 2007, 2010), three of which are located in the desert steppe of Inner Mongolia. This model has been verified in the mainland of China and has passed the 0.05 reliability test (Li et al., 2013). The general equation of this model is:

$$
G P P=F P A R \times P A R \times \varepsilon_{\max } \times \operatorname{Min}(f(T), f(W)) .
$$

Where GPP is the gross primary productivity $\left(\mathrm{g} \mathrm{C} / \mathrm{m}^{2}\right)$, FPAR refers to the ratio of plant canopy absorbing photosynthetically active radiation, and the product of FPAR and PAR is the fraction of PAR absorbed by plant canopy. Moreover, an Angstrom-type correlation method was used to calculate downward solar radiation $(R g)$ from the daylight hours data (Almorox and Hontoria, 2004; Yuan et al., 2013), and $R g$ was converted to photosynthetically active radiation $(P A R)$ using a ratio of $0.5 ; \varepsilon_{\max }$ is the utilization rate of potential light energy ( $2.14 \mathrm{~g} \mathrm{C} / \mathrm{MJ}), f(T)$ is the temperature limiting factor, and $f(W)$ is the water limiting factor.

FPAR is calculated as:

$$
F P A R=\mathrm{a} \times N D V I+\mathrm{b} .
$$

Where $\mathrm{a}=1.24$ and $\mathrm{b}=0.168$ are empirical parameters. The Normalized Difference Vegetation Index (NDVI) can be computed for most remotely sensed data. We used NDVI data from NOAA/AVHRR instruments. NDVI time series were obtained for 28 years (1982-2009) at the temporal resolution of 15 days and spatial resolution of $8 \mathrm{~km}$. We also made a monthly maximum composite by reselecting the maximum NDVI value from every two 15-day periods.

$f(T)$ is calculated as:

$$
f(T)=\frac{\left(T_{a}-T_{\min }\right)\left(T-T_{\max }\right)}{\left(T-T_{\min }\right)\left(T-T_{\max }\right)-\left(T-T_{\text {opt }}\right)^{2}} .
$$

Where $T_{a}$ is the monthly mean air temperature and
$T_{\min }$ and $T_{\max }$ are the minimum and maximum temperatures $\left({ }^{\circ} \mathrm{C}\right)$ for photosynthetic activity, respectively. If the air temperature falls below $T_{\min }$ or increases beyond $T_{\max }, f(T)$ is set to zero. $T_{\text {opt }}$ is the optimum air temperature, defined as the mean temperature of growing season. In this study, $T_{\min }$ and $T_{\max }$ were set to $0^{\circ} \mathrm{C}$ and $40^{\circ} \mathrm{C}$, respectively, while $T_{\text {opt }}$ would be determined using nonlinear optimization.

$f(W)$ is reflected using the evaporative fraction (EF) and is calculated as:

$$
E F=\frac{L E}{L E+H} .
$$

Where $L E$ and $H$ are ecosystem latent heat flux $\left(\mathrm{W} / \mathrm{m}^{2}\right)$ and ecosystem sensible heat flux $\left(\mathrm{W} / \mathrm{m}^{2}\right)$, respectively.

We applied EC-LUE to estimate the monthly GPP during 1982-2009. Yearly GPP was calculated by summing the GPP from January through December. Spatial and temporal variations of GPP were analyzed for three decades (1982-1990, 1991-2000 and 2001-2009). The temporal linear trends in GPP were estimated by regressing GPP along the year. Spatial heterogeneity of temporal variation in GPP (amplitude) was analyzed by simulating the trend variability of each grid using linear regression for every pixel. The least squares regression coefficient was calculated as:

$$
\text { Slope }=\frac{\sum_{i=1}^{n} x_{i} t_{i}-\frac{1}{n\left(\sum_{i=1}^{n} x_{i}\right)\left(\sum_{i=1}^{n} t_{i}\right)}}{\sum_{i=1}^{n} t_{i}{ }^{2}-\frac{1}{n}\left(\sum_{i=1}^{n} t_{i}\right)^{2}} .
$$

Where $i=1,2,3, \ldots, n$ is the number of years monitored, $x_{i}$ is the GPP of the $i^{\text {th }}$ year, and $t_{i}$ is the time. Positive slope represents an increasing trend with time, while a negative slope indicates a decreasing trend. The absolute value of the slope expresses the rate of 
increase or decrease.

Correlation analysis was used to determine the dominant climatic factors affecting phenology and GPP. Eight climatic factors were selected for GPP calculation: mean annual precipitation, annual mean temperature, growing season precipitation, growing season temperature, spring precipitation, spring temperature, summer precipitation and summer temperature. Twelve climatic factors were selected for greenup phenology, namely, temperature in a period of ten days, precipitation in a period of ten days, temperature during the last ten days, precipitation during the last ten days, January temperature, January precipitation, February temperature, February precipitation, March temperature, March precipitation, April temperature and April precipitation. Ten climatic factors were selected for senescing phenology, namely, temperature in a period of ten days, precipitation in a period of ten days, temperature during the last ten days, precipitation during the last ten days, July temperature, July precipitation, August temperature, August precipitation, September temperature and September precipitation.

ArcGIS 9.3 was used for kriging analysis of the spatial statistics of temperature, precipitation and GPP. Trend, regression and variance analyses were conducted using the Statistical Package for the Social Sciences Version 17.0 (SPSS Inc, Chicago, IL, USA).

\section{Results}

\subsection{Climate changes in the desert steppe of Inner Mongolia during the last 50 years}

\subsubsection{Temperature}

The annual average temperature of the desert steppe of Inner Mongolia increased by $0.033^{\circ} \mathrm{C}-0.113^{\circ} \mathrm{C}$ per year during 1961-2010. The southwestern part of this region showed the greatest increasing trend (Fig. 2a). Seasonally, the rising trend of temperature was most significant in winter, followed by autumn (Figs. $2 \mathrm{~b}-\mathrm{e}$ ). The annual average temperature and the average temperatures of spring, summer, autumn and winter were consistently higher than the 50-year average temperature after the 1990s. On average, the average temperature of last 10 years was the highest (Fig. 3).

\subsubsection{Precipitation}

The annual precipitation exhibited a decreasing trend in the north and southwest of the study area and a significant increasing trend in its eastern-central part (Fig. 4a). Seasonally, precipitation showed an increasing trend during spring and decreasing trend in summer. In autumn, precipitation showed a decreasing trend, while increased in winter for most regions (Figs. $4 b-e$ ). Temporal trends, it showed no significant change for annual, autumn and winter precipitation (Figs. 5a, 5d, $5 \mathrm{e}$ ) in the last 50 years. The only significant increase in spring precipitation and decrease in summer precipitation occurred in the last decade.

\subsection{Plant phenological changes in the desert steppe of Inner Mongolia}

Early green-up was observed in 4 observation stations $\left(2 / 3^{\text {rd }}\right)$ in the study area during 2004-2012, while the other two stations exhibited a delay in green-up (Table 1). Early senescence was observed in 4 stations, resulting in shortened growing seasons in these stations (Table 1). The general data from the 6 stations suggest the advance of spring, delay of autumn, and an overall shortening of the growing season in the desert steppe of Inner Mongolia (Table 1). It showed that the temperature during the last ten days was the dominant climatic factor for green-up phenology $(R=-0.788$, $P<0.01$ ), and the temperature in a period of ten days, which indirectly led to water deficit, was the dominant climatic factor for senescing phenology $(R=-0.859$, $P<0.01)$.

\subsection{GPP dynamics in the desert steppe of Inner Mongolia}

GPP varies significantly across the study area (Fig. $6 a)$. It is highest in the southeast and the northeast and decreases towards the western regions. This spatial distribution is positively correlated with the annual precipitation patterns (Fig. 6b). Due to scarce precipitation and sparse vegetation, the Inner Mongolian desert steppe is characterized by generally low GPP. The regions with GPP lower than $150 \mathrm{~g} \mathrm{C} / \mathrm{m}^{2}$ account for $82.5 \%$ of the total study area. This shows that precipitation, especially growing season precipitation and summer precipitation was dominant climatic factors for GPP $(R=-0.664, P<0.01)$. 


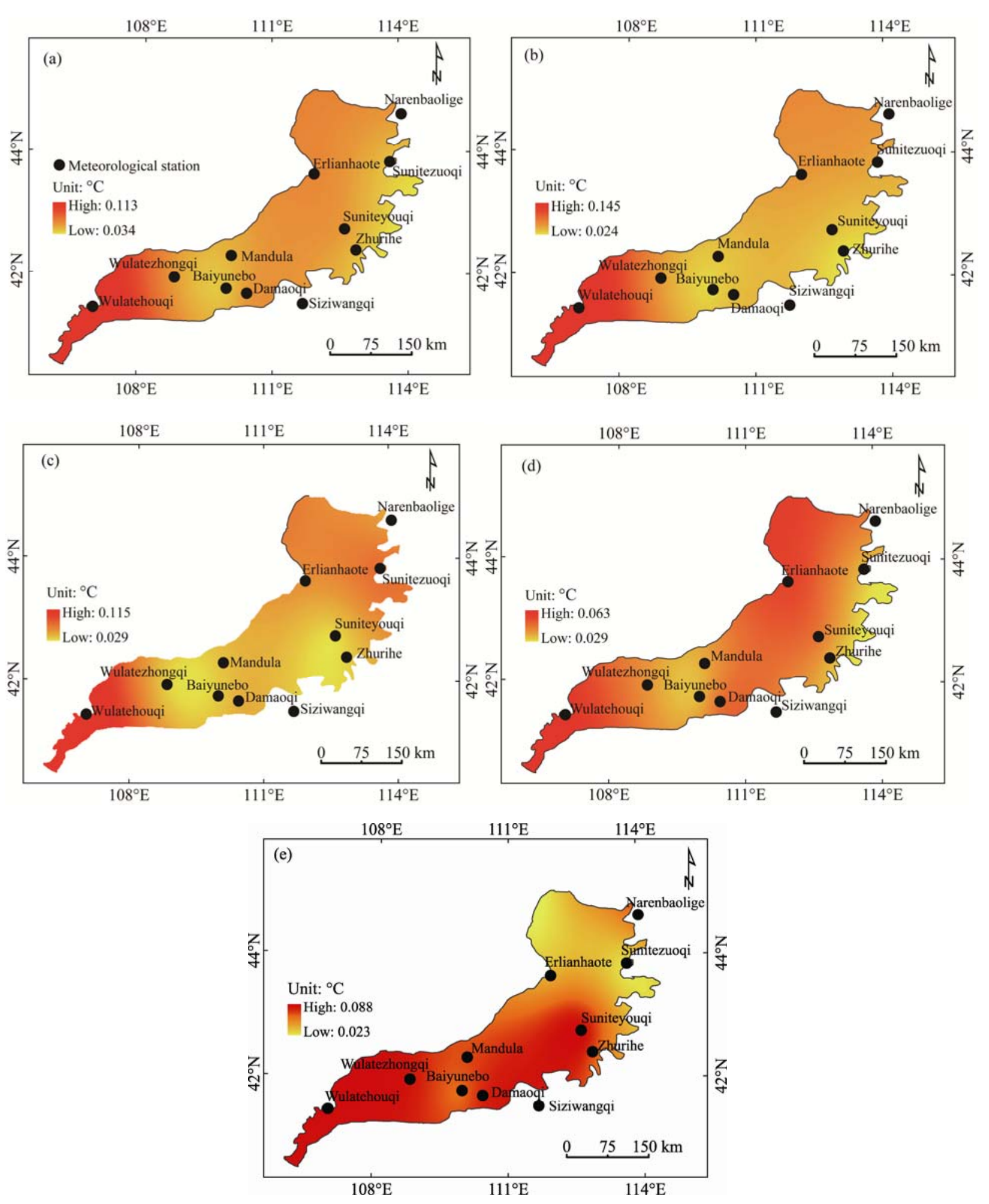

Fig. 2 Spatial patterns of increased mean temperature in the Inner Mongolian desert steppe during 1961-2010. (a), annual; (b), spring; (c), summer; (d), autumn; (e), winter.

The trend analysis of GPP pixels showed that in 1982-2009, the east-central part of the area, which accounts for more than $61.8 \%$ of the total area, expe- rienced a decrease in primary productivity, and southwestern part showed an increase in primary productivity (Fig. 7a). Individual analysis of the different 


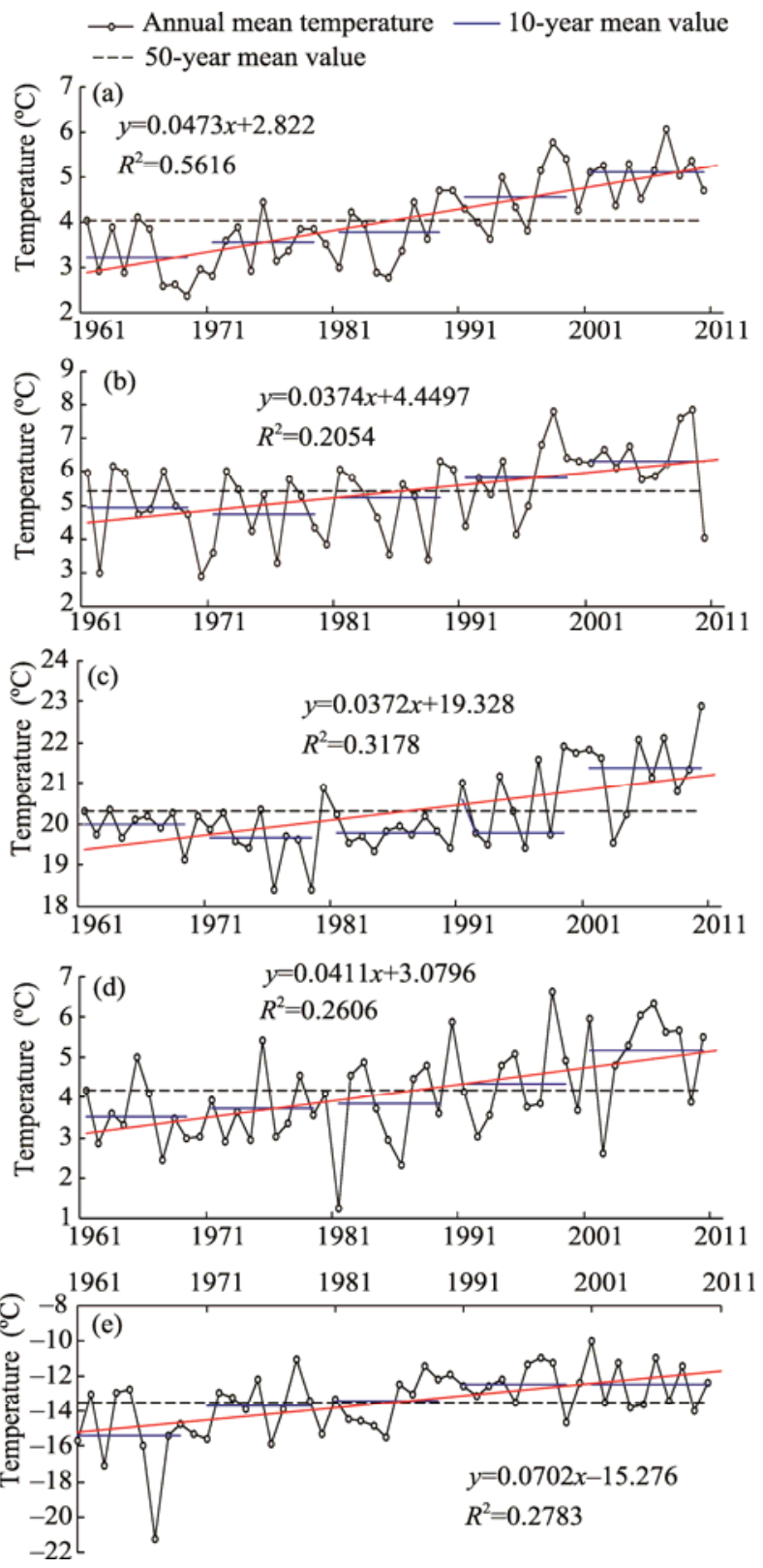

Fig. 3 Changes in mean temperature in the Inner Mongolian desert steppe during 1961-2010. (a), annual; (b), spring; (c), summer; (d), autumn; (e), winter.

decades (Figs. 7b-d) showed that in 1982-1990, about $73 \%$ of the area showed an increase in GPP, while during 1991-2000, 83\% of the area showed such an increase. The increase rate was higher in the 1990-2000. After 2000, about $62 \%$ of the study area experienced a decrease in primary productivity, with more than $55.66 \%$ of the area exhibiting the strongest declining trend $(<-2)$.

\section{Discussion}

\subsection{Characteristics of climate change in the desert steppe of Inner Mongolia}

Our study showed that the annual average temperature in the desert steppe of Inner Mongolia increased steadily during 1961-2010, with the most recent decade being appreciably warmer than the entire study period. Considerable differences were found for seasonal temperature trends. The most significant warming was noted in the winter season, followed by autumn and summer. These findings are consistent with those results in other regions (Shi et al., 2003). Our results suggest that climate warming in the desert steppe $\left(0.47^{\circ} \mathrm{C} / 10 \mathrm{a}\right)$ was higher than that in the other ecosystems of the Inner Mongolia autonomous region $\left(0.39^{\circ} \mathrm{C} / 10 \mathrm{a}\right)$ (Zhang et al., 2013) and all of China $\left(0.22^{\circ} \mathrm{C} / 10 \mathrm{a}\right)$ (Ren et al., 2005). We therefore consider the Inner Mongolian desert steppe to be quite unique in this regard and identify three major reasons. First, this desert steppe, located in the west of Inner Mongolia plateau, is characterized by arid climate (Inner Mongolia-Ningxia Joint Inspection Group of Chinese Sciences of Academy, 1985). Second, vegetation coverage of this area is very low. Exposed bare soil causes additional warming of ambient air (Zhang et al., 2012). Third, such a fragile ecosystem is highly susceptible to global climate warming, which causes rapid and intense response here (Bai et al., 2008).

As precipitation is the second most important component of climate change analyses, it is considered a key factor controlling vegetation growth in arid and semi-arid ecosystems. Our results suggest that during the last 50 years, precipitation in the Inner Mongolian desert steppe slightly decreased in variability and exhibited a declining trend at the rate of $1.883 \mathrm{~mm} / \mathrm{a}$. This rate was much lower than that of the entire Inner Mongolia autonomous region ( $-5.9 \mathrm{~mm} / \mathrm{a}$ ) (Ding and Chen, 2008). Moreover, such a decreasing trend is inconsistent with the slight increase in the mean annual precipitation in China (The National Climate Change Assessment Report Writing Committee, 2007). The interdecadal precipitation dynamics of the desert 


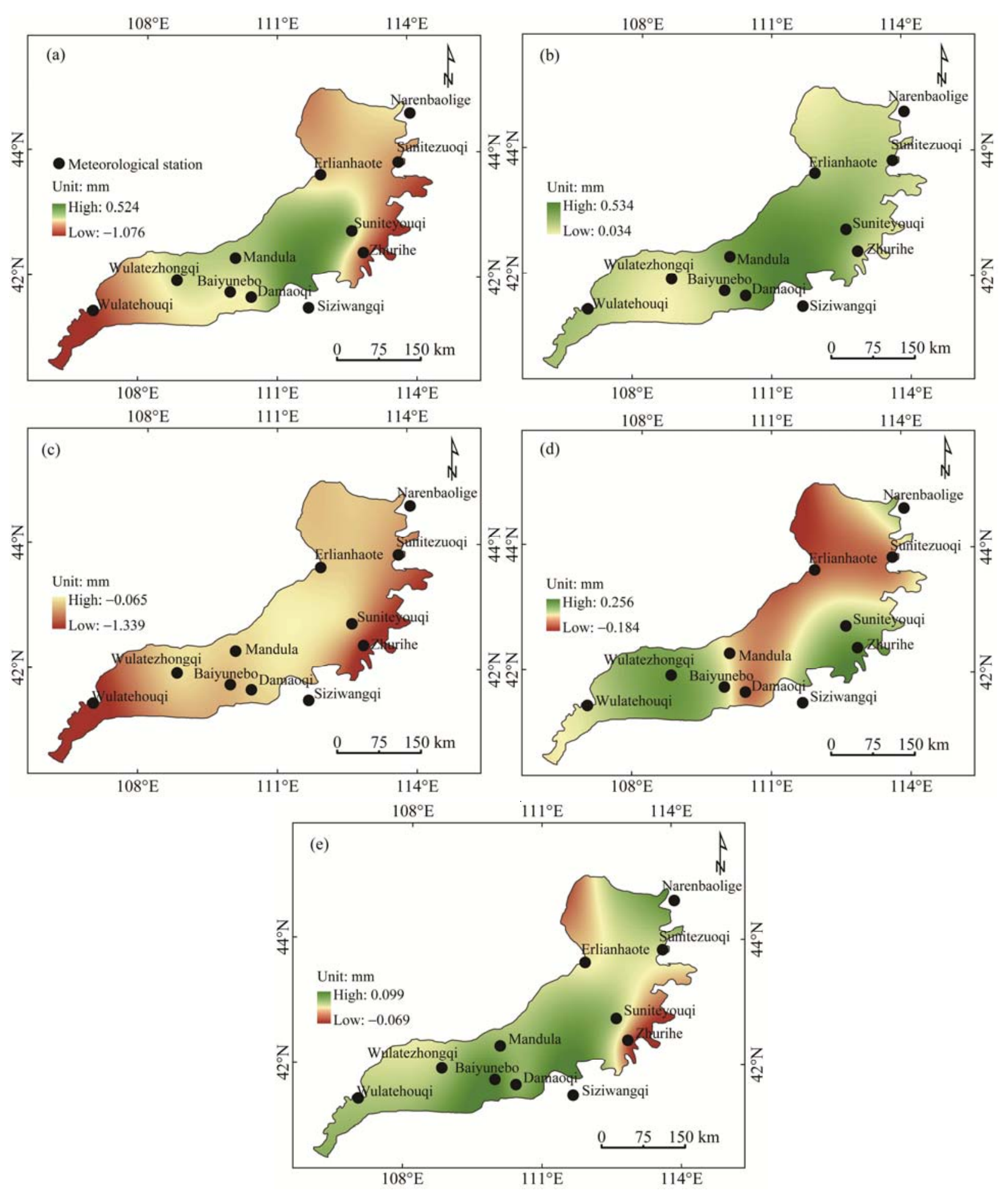

Fig. 4 Spatial patterns of annual precipitation change during the period of 1961-2010. (a), annual; (b), spring; (c), summer; (d), autumn; (e), winter.

steppe is in agreement with the climate change in the typical steppe, but differs from that of the meadow steppe in Inner Mongolia. Seasonally, precipitation in the desert steppe was found to increase in spring and decrease in summer. Understanding these trends is important for predicting future precipitation and vegetation growth patterns along with sustainability of animal husbandry in this region. 

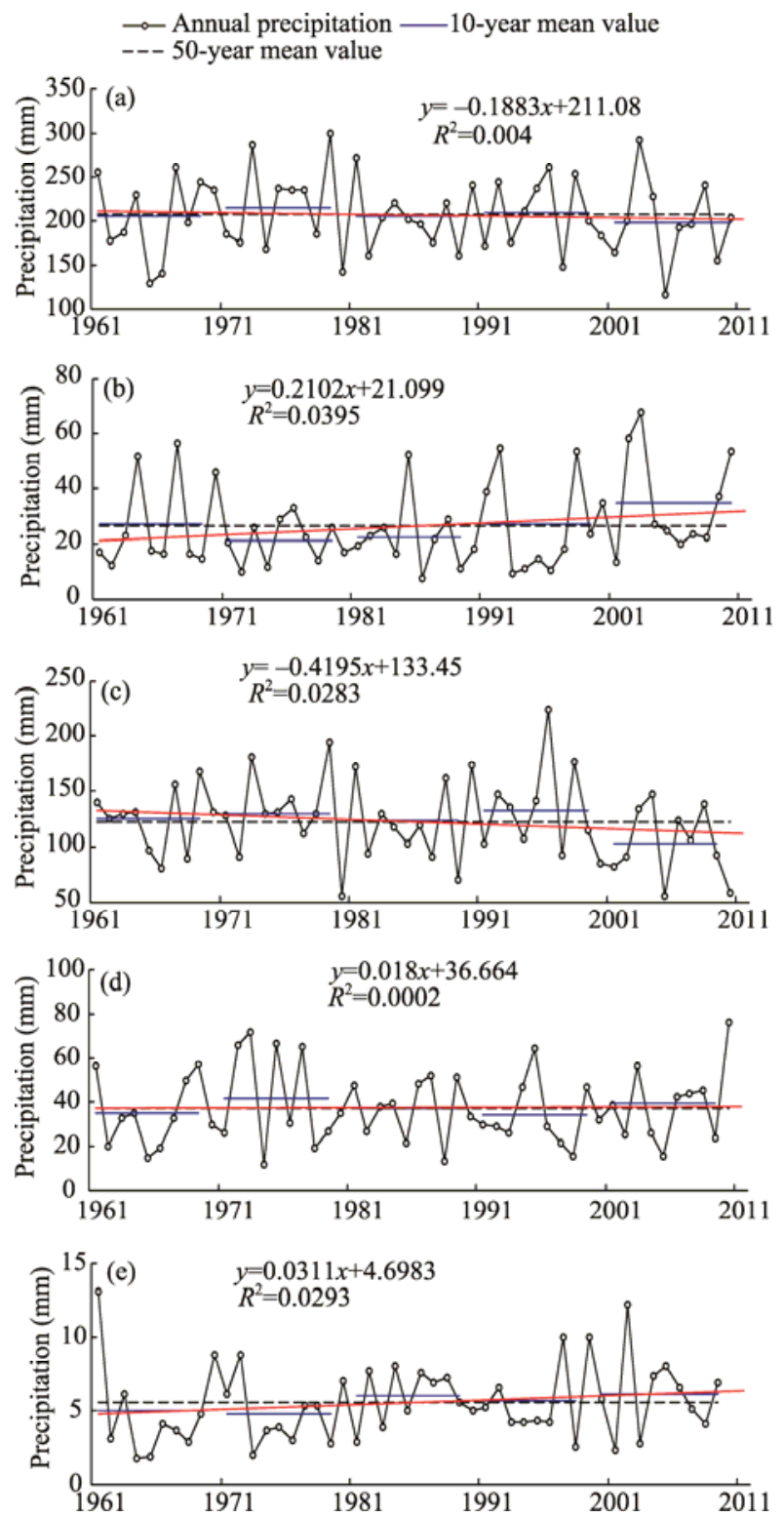

Fig. 5 Changes in mean annual precipitation in the Inner Mongolian desert steppe during the period of 1961-2010. (a), annual; (b), spring; (c), summer; (d), autumn; (e), winter.

\subsection{Effects of climate changes on plant phenol- ogy}

Changes in plant phenology often reflect climatic and environmental changes (Walther et al., 2002). Following global climate change, phenological events such as germination, leafing, blossoming and leaf shedding may occur in advance or delay. Subsequently, the length of the growing season may either decrease or increase. Plants would continue to undergo structural and functional adaptations to these environmental changes. The important consequences of these transformations are alterations in primary productivity, and water and heat exchanges within the soil-vegetation-atmosphere system, with feedbacks affecting the atmosphere and triggering further climate changes (Edwards and Richardson, 2004; Cleland et al., 2007).

Most previous studies have asserted that climate warming causes earlier onset of spring phenology, the delay of autumn phenological events and overall lengthening of the growing season (Sparks and Carey, 1995; Menzel, 2000). Furthermore, the expansion of the growing season allows plants to stay active for a longer period, positively affecting primary productivity (Myneni et al., 1997; Nemani et al., 2003). In our study, the increasing precipitation did not have any significant effects on the phenology of grasses. We found that although the desert steppe experienced earlier green-up, the length of the growing season decreased due to the earlier onset of autumn phenological events. This finding is inconsistent with the conclusion drawn by most previous researchers, who found that climate changes result in the extension of the growing season. However, it is in agreement with the previously reported transformations of Leymus chinensis phenology in Inner Mongolia (Chen and Li, 2009). The found that regional variations in precipitation increased in Inner Mongolia. Plant growth is somewhat limited by low temperatures in the most humid regions in eastern Inner Mongolia. In the central and western parts, precipitation is the most important determinant of plant growth. Being located in the north-central part of Inner Mongolia, the desert steppe is characterized by hot and dry climate. Climate changes in this area, namely, the increases in temperature and winter and spring precipitation in the last 10 years, resulted in the advancement of green-up. Autumn phenophases also occurred earlier due to the increased temperature and decreased summer and autumn precipitation. Consequently, the growing seasons shortened, with important consequences for productivity, plant community structure and ecosystem functioning. 

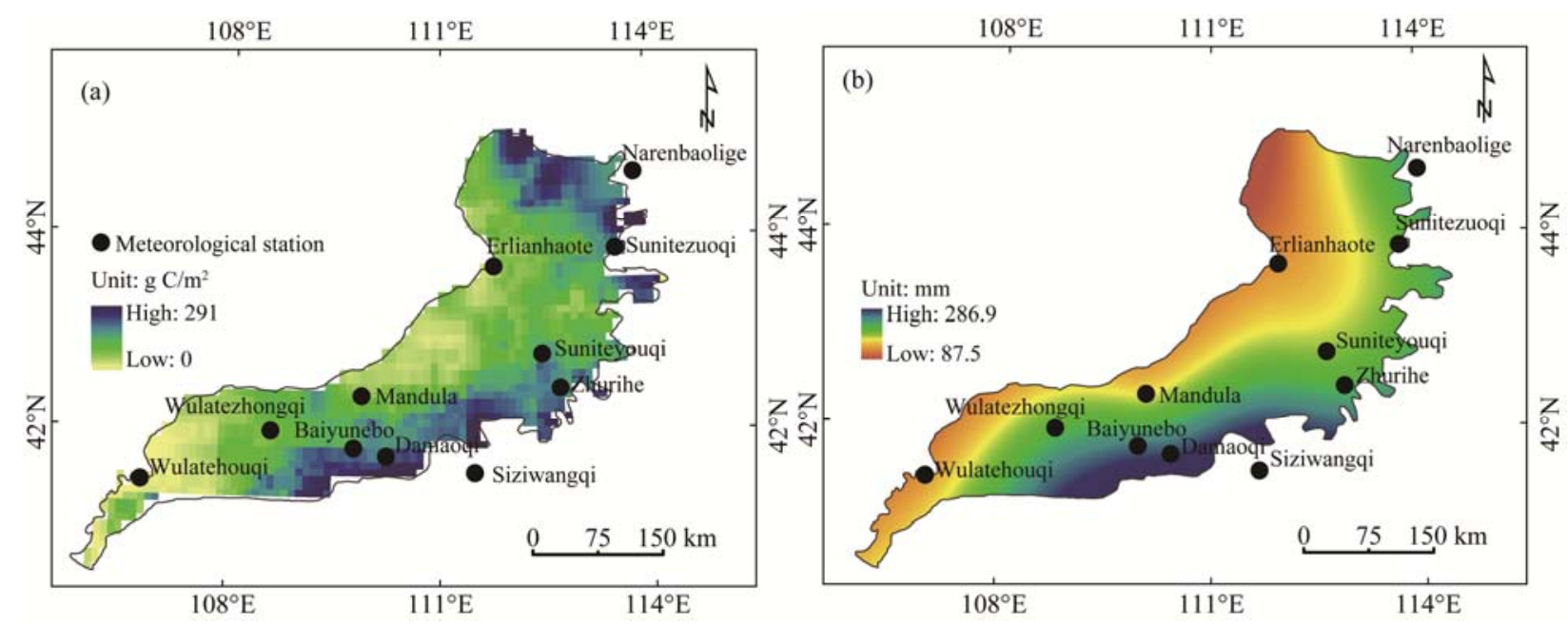

Fig. 6 Spatial distribution of the mean gross primary productivity (GPP) during the period of 1982-2009 (a) and precipitation during the period of 1961-2010 in the Inner Mongolian desert steppe (b)
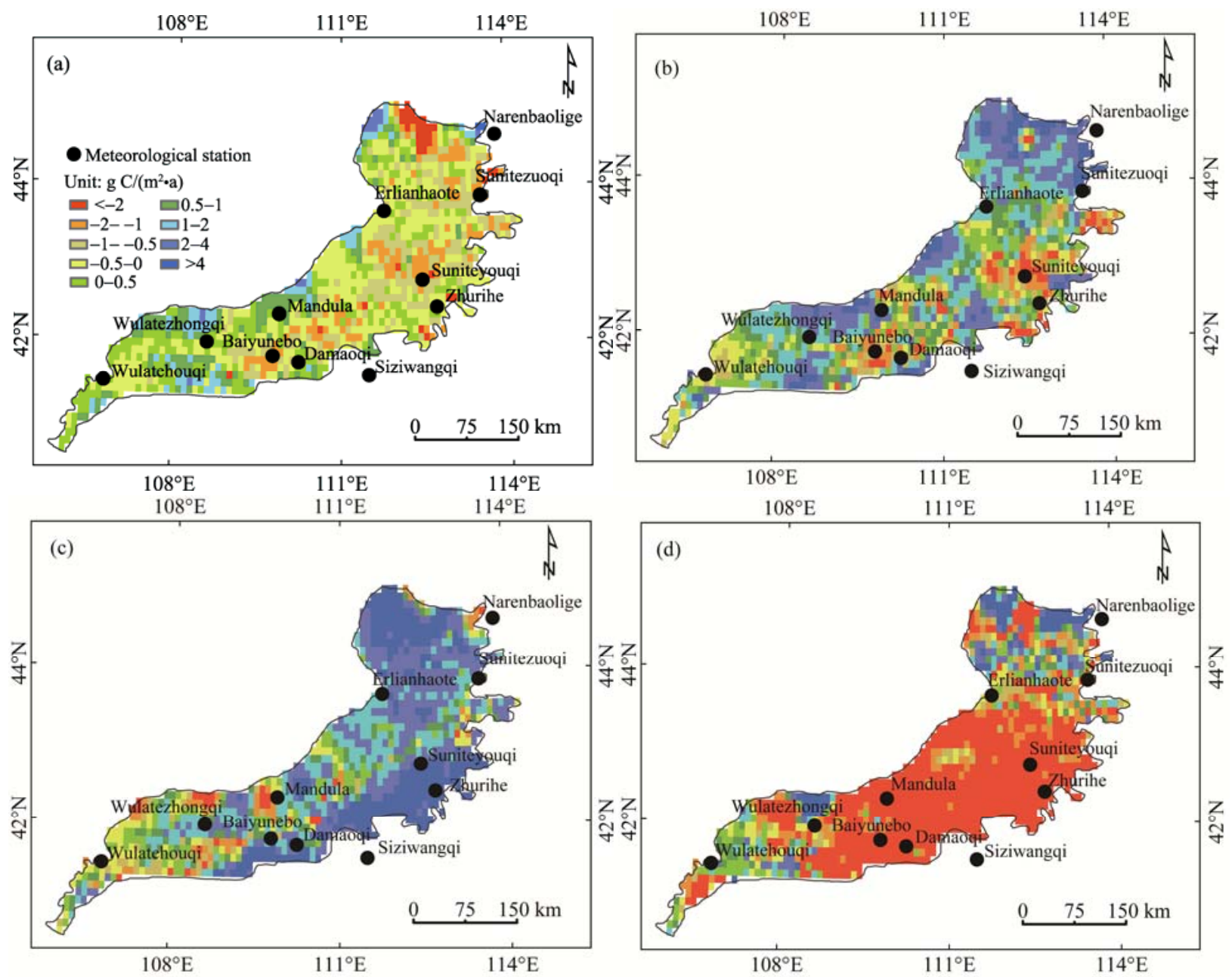

Fig. 7 Spatial distribution of the change of mean annual gross primary productivity (GPP) in the Inner Mongolian desert steppe. (a), 1982-2009; (b), 1982-1990; (c), 1991-2000; (d), 2001-2009. 


\subsection{Primary productivity patterns in the desert steppe of Inner Mongolia}

Primary productivity reflects environmental conditions and could be used to characterize the quality of terrestrial ecosystems. It is an important ecological variable suitable for estimating the resilience of ecosystems (Ruimy et al., 1994; Field et al., 1998). As such, primary productivity and its response to climate changes have been at the core of global change research (Fang et al., 2003; Piao et al., 2005)

Global patterns of NPP (GPP minus respiration) showed 6.17\% increase (3.4 Pg C) during 1982-1999 (Nemani et al., 2003). NPP also exhibited an increasing trend at the scale of entire North America, where it showed 8\% increase during 1982-1998 (Hicke et al., 2002), and in the whole China, where it increased by 18.7\% between 1982 and 1999 (Fang et al., 2003). These trends are also consistent at the level of the typical steppe of Inner Mongolia, but our analyses of GPP in the Inner Mongolian desert steppe during 1982-2009 showed an opposite trend (Fig. 7). Yet, at the decadal scale, both trends are present - the increase during 1982-1999 and decrease during 2000-2009 - especially in the central part of the study area. Such dramatic fluctuations at the decadal level are an important proof of the high temporal variability of this system, which is highly susceptible to precipitation changes.

Precipitation and temperature are the principal environmental driving factors affecting vegetation productivity (Nemani et al., 2003; Piao et al., 2006). As previously mentioned, the Inner Mongolian desert steppe belongs to the temperate continental climate with high temperature and little rainfall. Inter-annual fluctuations of productivity in the desert steppe are mainly driven by annual precipitation. Generally, the higher the annual precipitation, the more productive is the desert steppe. It should also be noted that productivity in the area is affected by the seasonal distribution of precipitation. Spring and early summer precipitation largely determine the changes in community biomass above the ground. This is almost a universal pattern for both the dry desert steppe and the typical steppe (Ma et al., 2010). Influenced by climatic factors, temperature and precipitation, the GPP of the
Inner Mongolian desert steppe exhibited significant temporal and spatial fluctuations. The GPP of the desert steppe declined in response to the rising temperature and decreasing annual and summer precipitation but increasing spring precipitation. Spatially, the GPP of this ecosystem highly correlates with annual precipitation.

\section{Conclusions}

During 1961-2010, the annual mean temperature increased at a rate of $0.47^{\circ} \mathrm{C} / 10 \mathrm{a}$, and annual precipitation slightly decreased during the 50 -year period. However, in the past 10 years, the Inner Mongolian desert steppe has witnessed severe climate changes, including significant warming in temperature, increase in spring precipitation, and decrease in summer precipitation. Plant phenology responded by advancing the green-up and senescence, consequently shortening the growing season. The GPP of the desert steppe also substantially decreased. These changes reduce the carbon sequestration capacity and its effectiveness in the carbon balance of the desert steppe ecosystem. As a result, local production and the entire livelihood of local farmers and herdsmen are jeopardized.

Traditional subsistence agriculture in the desert steppe is vulnerable to climate changes. While production of pastures and livestock is at risk, integrated scientific and policy analyses are required in order to develop plans and strategies to mitigate the effects of climate change on agricultural production and animal husbandry. First, rational utilization of grassland and implementation of rest grazing, rotational grazing, seasonal grazing and a series of other measures are required. It is necessary for governments to implement economic compensation to pastoralists under these policies. Second, goat husbandry is not appropriate in the desert steppe. Structural changes in livestock are necessary, such as replacement of goats by bigger livestock, horses and camels, which are more suitable for this area (Hou et al., 2012). Third, it is governments' responsibility to improve infrastructure and build additional stables for herders. Adaptions to climate change will also increase if forage reserves are properly secured. 


\section{Acknowledgements}

The study was supported by the State Key Basic Research Development Program of China (2012CB722201), the National Basic Research Program of China (31200414, 31060320, 30970504), the National Basic Research Program of Inner Mongolia (2009ms0603) and the Earmarked Fund for Modern Agro-Industry Technology Research System. We thank the editor and two anonymous reviewers for the comments on the early version of this manuscript.

\section{References}

Almorox J, Hontoria C. 2004. Global solar radiation estimation using sunshine duration in Spain. Energy Conversion and Management, 45: 1529-1535.

Bachu S, Adams J. 2003. Sequestration of $\mathrm{CO}_{2}$ in geological media in response to climate change: capacity of deep saline aquifers to sequester $\mathrm{CO}_{2}$ in solution. Energy Conversion and Management, 44: 3151-3175.

Bai Y F, Han X G, Wu J G, et al. 2004. Ecosystem stability and compensatory effects in the Inner Mongolia grassland. Nature, 431: 181-184.

Bai Y F, Wu J G, Xing Q, et al. 2008. Primary production and rain use efficiency across a precipitation gradient on the Mongolia plateau. Ecology, 89: 2140-2153.

Chen X Q, Hu B, Yu R. 2005. Spatial and temporal variation of phenological growing season and climate change impacts in temperate eastern China. Global Change Biology, 11: 1118-1130.

Chen X Q, Li L. 2009. Relationship between phenology of Leymus chinensis grassland and meteorological factors. Acta Ecologica Sinica, 29: 5280-5290. (in Chinese)

Cleland E E, Chuine I, Menzel A, et al. 2007. Shifting plant phenology in response to global change. Trends in Ecology and Evolution, 22: 357-365.

Cornelissen J H, Van Bodegom P M, Aerts R, et al. 2007. Global negative vegetation feedback to climate warming responses of leaf litter decomposition rates in cold biomes. Ecology Letters, 10: 619-627.

Ding X H, Chen T Z. 2008. Climate change of Inner Mongolia during past 50 years. Meteorology Journal of Inner Mongolia, 3: 17-19. (in Chinese)

Edwards M, Richardson A J. 2004. Impact of climate change on marine pelagic phenology and trophic mismatch. Nature, 430: 881-884.

Fang J Y, Piao S L, Field C B, et al. 2003. Increasing net primary production in China from 1982 to 1999. Frontiers in Ecology and the Environment, 1: 293-297.

Fang J Y, Piao S L, Zhou L M, et al. 2005. Precipitation patterns alter growth of temperate vegetation. Geophysical Research Letters, 32: L21411.

Field C B, Behrenfeld M J, Randerson J T, et al. 1998. Primary production of the biosphere: integrating terrestrial and oceanic components. Science, 281: 237-240.

Gu R Y, Zhou W C, Bai M L, et al. 2012. Impacts of climate change on phenological phase of herb in the main grassland in Inner Mongolia.
Acta Ecologica Sinica, 32: 767-776. (in Chinese)

Hicke J A, Asner G P, Randerson J T, et al. 2002. Satellite-derived increases in net primary productivity across North America, 1982-1998. Geophysical Research Letters, 29: 69-1-69-4.

Hou X Y, Han Y, Li Y H. 2012. The perception and adaptation of herdsmen to climate change and climate variability in the desert steppe region of northern China. Rangeland Journal, 34: 349-357.

Inner Mongolia-Ningxia Joint Inspection Group of Chinese Academy of Sciences. 1985. Vegetation of Inner Mongolia. Beijing: Science Publishing House. (in Chinese)

IPCC. 2007. Climate change 2007: The Physical Science Basis. Contribution of Working Group I to the Fourth Assessment Report of the Intergovernmental Panel on Climate Change. Cambridge: Cambridge University Press.

Li X L, Liang S L, Yu G R, et al. 2013. Estimation of gross primary production over the terrestrial ecosystems in China. Ecological Modelling, 261: 80-92.

Ma W H, He J S, Yang Y H, et al. 2010. Environmental factors covary with plant diversity-productivity relationships among Chinese grassland sites. Global Ecology and Biogeography, 19: 233-243.

Menzel A. 2000. Trends in phenological phases in Europe between 1951 and 1996. International Journal of Biometeorology, 44: 76-81.

Menzel A, Sparks T H, Estrella N, et al. 2006. European phenological response to climate change matches the warming pattern. Global Change Biology, 12: 1969-1976.

Myneni R B, Keeling C, Tucker C, et al. 1997. Increased plant growth in the northern high latitudes from 1981 to 1991. Nature, 386: 698-702.

Nemani R R, Keeling C D, Hashimoto H, et al. 2003. Climate-driven increases in global terrestrial net primary production from 1982 to 1999. Science, 300: 1560-1563.

Piao S L, Fang J Y, Zhou L M, et al. 2005. Changes in vegetation net primary productivity from 1982 to 1999 in China. Global Biogeochemical Cycles, 19.

Piao S L, Mohammat A, Fang J Y, et al. 2006. NDVI-based increase in growth of temperate grasslands and its responses to climate changes in China. Global Environmental Change, 16: 340-348.

Piao S L, Fang J Y, Ciais P, et al. 2009. The carbon balance of terrestrial ecosystems in China. Nature, 458: 1009-1013.

Ren G Y, Guo J, Xu M Z, et al. 2005. Characteristics of terrestrial climate change in China during past 50 years. Meteorological Bulletin, 942-956. (in Chinese)

Ruimy A, Saugier B, Dedieu G. 1994. Methodology for the estimation of terrestrial net primary production from remotely sensed data. Journal of Geophysical Research: Atmospheres, 99: 5263- 5283.

Shi Y F, Shen Y P, Li D L, et al. 2003. Discussion on the present climate change from warm-dry to warm-wet in northwest China. Quaternary Sciences, 23: 152-164. (in Chinese)

Sparks T, Carey P. 1995. The responses of species to climate over two centuries: an analysis of the Marsham phenological record, 1736-1947. Journal of Ecology, 83: 321-329.

Stenseth N C, Mysterud A, Ottersen G, et al. 2002. Ecological effects of climate fluctuations. Science, 297: 1292-1296.

The National Climate Change Assessment Report Writing Committee. 2007. The National Climate Change Assessment Report. Beijing: 
Science Press. (in Chinese)

Walther G R, Post E, Convey P, et al. 2002. Ecological responses to recent climate change. Nature, 416: 389-395.

Yuan W P, Liu S G, Zhou G S, et al. 2007. Deriving a light use efficiency model from eddy covariance flux data for predicting daily grossprimary production across biomes. Agricultural and Forest Meteorology, 143: 189-207.

Yuan W P, Liu S G, Yu G R, et al. 2010. Global estimates of evapotranspiration and gross primary production based on MODIS and global meteorology data. Remote Sensing of Environment, 114: 1416-1431.

Yuan W P, Liu D, Dong W J, et al. 2013. Multiyear precipitation reduction strongly decrease carbon uptake over North China. Biogeosciences Discussions, 10: 1605-1634.

Yun W L, Hou Q, Wulanbateer. 2008. Impacts of climate change over last 50 years on net primary productivity in typical steppe of Inner Mongolia. Chinese Journal of Agrometeorology, 29: 294-297. (in Chinese)

Zhang C H, Wang M J, Zhang L, et al. 2013. Responses of aboveground net primary productivity to climate change in Hulunbel meadow grassland. Acta Prataculturae Sinica, 22(3): 41-50. (in Chinese)

Zhang F, Zhou G S, Wang Y, et al. 2012. Evapotranspiration and crop coefficient for a temperate desert steppe ecosystem using eddy covariance in Inner Mongolia, China. Hydrological Processes, 26: 379-386. 